\title{
Ni POSITIVISMO JURÍDICO \\ NI NEOCONSTITUCIONALISMO: \\ UNA DEFENSA DEL CONSTITUCIONALISMO \\ POSTPOSITIVISTA ${ }^{1}$
}

MANUEL ATIENZA ${ }^{2}$

\section{RESUMEN}

El proceso de constitucionalización en los sistemas jurídicos del mundo occidental ha generado un interesante debate; por un lado, se presenta el positivismo jurídico (con sus variantes), que principalmente entiende al Derecho como conjunto de normas, cuyo atributo más importante se halla en la autoridad y forma de su expedición, desligada totalmente de la moral; y por otro lado, el llamado "neoconstitucionalismo", que en total oposición al anterior, ve al Derecho como un conjunto de principios (reconocidos en la Constitución), cuya aplicación es meramente valorativa y sustantiva y, por lo tanto, requiere la moral en el Derecho. Frente a estos escenarios antagónicos y hasta cierto punto insostenibles, se presenta, como alternativa, el constitucionalismo postpositivista. Éste concibe al Derecho de una manera más amplia, completa y compleja, que incluye

1 Artículo entregado por el autor el 9 de junio de 2016 y aprobado el 17 de mayo de 2017.

2 Abogado, catedrático de filosofía del Derecho de la Universidad de Alicante y director de la Revista Doxa. Ha sido profesor en la Universidad Autónoma de Madrid y la Universidad de Valencia, así como de la Academia Europea de Teoría del Derecho. Ha sido profesor visitante en numerosas universidades de Europa y América. 
aspectos descriptivos, normativos y valorativos, orientando la práctica del jurista en el contexto del Estado Constitucional.

\section{PALABRAS CLAVE}

Neoconstitucionalismo, constitucionalización, positivismo jurídico, postpositivismo constitucionalista

\section{ABSTRACT}

The process of founding constitutions in the legal systems of the Western world has generated an interesting debate; on the one hand, legal positivism (with its variants), which principally understands Law as a set of rules, whose most important attribute lies on the authority and the way it is expedited, totally detached from morality. On the other hand, the so-called "neoconstitutionalism", which in total opposition to the previous one, sees the Law as a set of principles (recognized in the Constitution) whose application is purely evaluative and substantive, and therefore, requires morality in Law. Facing these antagonistic and to some extent unsustainable scenarios, postpositivist constitutionalism appears as an alternative. It conceives Law in a broader, more complete, and complex way, which includes descriptive, normative and value aspects, guiding the practice of the jurist in the context of a Constitutional State.

\section{KEY WORDS}

Neo-constitucionalism, process of founding constitutions, legalpositivism, postpositive constitucionalism 
$\mathrm{Si}$ alguien me preguntara hoy ¿qué es eso del neoconstitucionalismo?, creo que le contestaría lo mismo o algo muy semejante a lo que aparece en el Diccionario de los lugares comunes de FLAUBERT, en relación con el Derecho: "No se sabe qué es". No estoy diciendo que yo no lo sepa, sino que no se sabe, que no se puede saber. Pero si lo que se me preguntara fuera si yo soy o no un neoconstitucionalista, mi respuesta inequívoca, incluso enfática, sería que no. Tampoco, por cierto, me considero un iuspositivista (de ninguno de los diversos tipos ahora existentes), aunque sí creo saber qué significa centralmente ser un autor iuspositivista. Veamos si soy capaz de explicar lo que en principio tiene todo el aire de una paradoja.

El término "neoconstitucionalismo" o "neoconstitucionalista" ha adquirido, como todo el mundo sabe, un gran predicamento en la teoría del Derecho de los países latinos -europeos y americanosen los últimos años. Pero no parecen existir expresiones equivalentes en otros ámbitos culturales; o, si existen, tienen un significado muy diferente. La procedencia de la expresión parece estar en la escuela genovesa, en varios representantes de la misma, que la introdujeron con un propósito manifiestamente crítico y descalificador: para referirse a una concepción del Derecho contraria al positivismo jurídico que ellos profesaban y profesan: digamos, al iuspositivismo metodológico o conceptual (la connotación de iuspositivismo realista podemos dejarla aquí de lado). Probablemente ese origen polémico tenga que ver con el uso tan confuso al que la expresión ha dado lugar. 
La confusión se debe, en principio, a una serie de ambigüedades que arrastra el término, más o menos obvias, pero de las que no siempre es consciente quien lo utiliza. Es evidente, por ejemplo, que a veces se habla de "neoconstitucionalismo" para referirse a un determinado fenómeno (ciertos cambios que han tenido lugar en los sistemas jurídicos en los últimos tiempos: la existencia de constituciones con ciertas características y que desempeñan un papel especialmente relevante en el conjunto del ordenamiento jurídico), pero otras veces (y en ocasiones al mismo tiempo) a la conceptualización de ese fenómeno: el neoconstitucionalismo como teoría del Derecho. Que el neoconstitucionalismo puede entenderse, esencialmente, como una doctrina (o un fenómeno) político, aunque también cabe poner el acento en su dimensión jurídica. O que a veces se usa el término para referirse a teorías o fenómenos que conciernen exclusivamente al Derecho constitucional (la interpretación de la Constitución, por ejemplo), mientras que en otras ocasiones el universo del discurso es el ordenamiento jurídico en su conjunto. Y por si esto fuera poco (o, si se quiere, como consecuencia de todos esos sentidos amontonados), el prefijo "neo" viene todavía a aumentar la confusión: pues en algunos de los anteriores significados puede comprenderse que se use esa expresión, "neoconstitucionalismo", pero la misma resulta desconcertante si a lo que queremos referirnos es a una teoría -a una concepción-general del Derecho: simplemente porque no ha habido ninguna anterior que pudiera llamarse (que se haya llamado) "constitucionalista". De manera que el "neo", simplemente, está de más, y uno está tentado a pensar que el éxito que ha conocido pudiera deberse a razones semejantes a las que hacen que se prefiera hablar de "influenciar" en lugar de "influir", de "concretizar" en lugar de "concretar" o de "direccionar" en lugar de "dirigir". O sea, una corrupción 
de la lengua basada en la falsa impresión de que alargar una palabra es una forma de agregarle sofisticación, profundidad a su significado.

Demos entonces un paso más y centrémonos en el que podría considerarse como significado principal de la expresión, al menos cuando quienes hacen uso de la misma son filósofos del Derecho: el (neo)constitucionalismo como concepción o teoría general del Derecho. De hecho, el artículo que suele considerarse como el primero en introducir la expresión es uno de Susana POZZOLO (1998): "Neoconstitucionalismo y especificidad de la interpretación constitucional". Pues bien, en el mismo, la noción de "neoconstitucionalismo" dista, en mi opinión, de estar clara. Lo caracteriza en términos de alternativa: principios versus normas (reglas), ponderación versus subsunción, Constitución versus independencia del legislador, y jueces versus libertad del legislador. Los neoconstitucionalistas serían entonces aquellos autores que subrayan la prevalencia del primero de los términos en cada una de esas oposiciones. Pero esto, sin duda, es muy poco claro, y cuando POZZOLO lo especifica, yo creo que se aparta significativamente de lo que defienden los autores que ella incluye bajo ese rótulo: DWORKIN, ALEXY, ZAGREBELSKY y "sólo en parte" NINO (POZZOLO Neoconstitucionalismo 339). Así, no me parece que sea cierto que ellos animen a los jueces a recurrir en la mayor medida posible a los principios, ni que planteen la ponderación como un procedimiento casuístico, que prescindan como criterio interpretativo de la deferencia al legislador o que promuevan que los jueces lleven a cabo una "interpretación moral del caso", puesto que "ahora el juez debe interpretar el Derecho a la luz de las exigencias de justicia vehiculadas por el caso" (POZZOLO Neoconstitucionalismo 342). 
En trabajos posteriores, POzzolo subraya la ambigüedad de la expresión "neoconstitucionalismo" y la analiza en términos en mi opinión más adecuados, en cuanto insiste sobre todo en el carácter no positivista de las tesis de los anteriores autores. Pero, aparte de lo desacertado de la expresión, creo que se equivoca también al pensar que esos autores terminan por "reducir lo normativo del Derecho, justamente, a la moral" (POzZOLO 2003 195), o que "[1] o que permitiría, en última instancia, calificar como "jurídico" un sistema normativo o una norma singular, por tanto, sería el contenido de justicia que expresaran" (POZzOLO Un constitucionalismo 191). El error, en mi opinión, consiste en que ella no ve que los autores a los que se refiere no tratan de "reducir" el Derecho a la moral, sino de defender que el Derecho implica también un elemento moral, valorativo. Sobre esto volveré más adelante.

Otra caracterización del (neo)constitucionalismo que ha tenido cierta fortuna (y está, desde luego, en línea con la anterior), es la de Paolo COMANDUCCI (2003), quien parte de la triple distinción que воввіо efectúa entre el positivismo jurídico en cuanto teoría, en cuanto ideología y en cuanto enfoque o método y traslada ese esquema al neoconstitucionalismo. Se trata entonces de ver cómo se contrapone positivismo jurídico y neoconstitucionalismo.

Pues bien, el neoconstitucionalismo en cuanto teoría se opondría a tesis como la del estatalismo, el legicentrismo o el formalismo interpretativo, que fueron defendidas por los positivistas de épocas anteriores (del XIX) y que a COMANDUCCI le parecen obsoletas. En ese sentido, él considera aceptable la teoría del neoconstitucionalismo, o sea, una teoría que trata de dar cuenta de las nuevas realidades de nuestros Derechos y, por tanto, del cambio que supone que las normas constitucionales 
se sitúen en el vértice de nuestros ordenamientos jurídicos; piensa incluso que esa nueva teoría puede considerarse como “el positivismo jurídico de nuestros días". Pero con ello se está refiriendo a un neoconstitucionalismo en sentido débil, esto es, el neoconstitucionalismo que profesarían quienes consideran la Constitución simplemente como un conjunto de normas que se diferencian de las otras (de las legislativas) por tener una jerarquía superior. No valdría para quienes suscriben una "versión fuerte" del neoconstitucionalismo, esto es, quienes asumen un concepto sustantivo o valorativo de Constitución que les lleva a defender que la ciencia del Derecho tiene también un carácter normativo, de manera que no es meramente descriptiva o explicativa (FERRAJOLI) o que la ciencia del Derecho debe elaborarse desde un punto de vista interno, de manera que sus cultivadores tienen que adherirse a los valores constitucionales (ZAGREBELSKY).

Precisamente, en cuanto ideología, el neoconstitucionalismo se caracterizaría por valorar positivamente el proceso de constitucionalización de nuestros Derechos y por propugnar su defensa y ampliación. Pero, a partir de ahí, y de la tesis de la necesaria conexión entre el Derecho y la moral, muchos de sus promotores (COMANDUCCI cita a ALEXY, a DWORKIN y a ZAGREBELSKY) pasan a sostener la tesis de la obligación moral de obedecer a la Constitución y eso hace que ese neoconstitucionalismo pueda ser considerado como una variante del positivismo ideológico, es decir, de la doctrina (errónea y peligrosa) que predica la obligación moral de obedecer el Derecho.

Y, en fin, en cuanto metodología, algunas variantes de neoconstitucionalismo, según COMANDUCCI, defienden la tesis de la conexión necesaria, identificativa y/o justificativa entre el Derecho 
y la moral. Frente al positivismo metodológico o conceptual en el que se sitúa COMANDUCCI, que sostiene que siempre es posible identificar y describir el Derecho como es y distinguirlo del Derecho como debería ser, lo que estos autores neoconstitucionalistas dirían es que los principios constitucionales vienen a ser como un puente entre el Derecho y la moral y que cualquier decisión jurídica (en particular judicial) está justificada si deriva en última instancia de una norma moral. Pero esto le parece a COMANDUCCI rechazable: si se interpreta como tesis descriptiva, es falsa, porque los jueces justifican sus decisiones ofreciendo razones que son normas jurídicas y no morales; y si se entiende como tesis teórica, además de tautológica (los neoconstitucionalistas -escribe-asumen que, "por definición”, toda justificación última en el dominio práctico está constituida por una norma moral), sería insostenible o bien inútil o, en todo caso, contraria a los propios valores democráticos.

Pues bien, esa caracterización del neoconstitucionalismo permite matizar algunas cosas, en cuantolleva a una comparación, digamos, sistemática entre el neoconstitucionalismo y el positivismo jurídico. Pero sigue presentando varios problemas. Por un lado, COMANDUCCI no justifica (o no lo hace satisfactoriamente) por qué emplear esa expresión, "neoconstitucionalismo", en lugar de "constitucionalismo" o "no-positivismo". Por otro lado, el esquema bobbiano del que parte para caracterizar el positivismo jurídico, a pesar de su gran difusión, no me parece muy convincente: prueba de ello es que un autor, yo creo que inequívocamente positivista, como FERRAJOLI, no lo sería sin embargo en ninguno de los tres sentidos anteriores (tampoco en sentido metodológico, pues FERRAJOLI (2012) considera que con el constitucionalismo -con la presencia en nuestros sistemas de constituciones rígidas- se habría producido una especie de identificación entre el ser y el deber ser del Derecho, el final 
de la contraposición entre el Derecho positivo y el Derecho natural, entre Creonte y Antígona. Y, finalmente, COMANDUCCI incluye, bajo el rótulo de "neoconstitucionalismo", concepciones del Derecho muy distintas entre sí y de las que, además, no da cuenta adecuadamente. De nuevo, lo que muchos de esos autores sostienen es algo distinto, en mi opinión, de lo que COMANDUCCI piensa que sostienen. Pero como antes decía, este punto lo trataré más adelante.

Una visión radicalmente crítica del neoconstitucionalismo puede encontrarse también en diversos trabajos de Juan Antonio GARCíA AMADO (2008). Tan crítica que, a pesar de reconocer que se trata de una categoría sumamente difusa a la que "son adscritos" (no que ellos mismos se adscriban) autores como DWORKIN, ALEXY, NINO O ZAGREBELSKY (son los únicos nombres que menciona), parece hacerles responsables (o corresponsables) de esa indefinición, lo que viene a ser como responsabilizar a los mulatos de contribuir a oscurecer, dado el color de su piel, la noción de "blanco" o de "negro". En todo caso, GARCÍA AMADO señala tres componentes filosóficos "muy rotundos" que tendría el neoconstitucionalismo (se supone que cualquier neoconstitucionalismo, o sea, que esas notas podrían encontrarse en todos los autores antes mencionados por él):

En lo ontológico, el objetivismo derivado de afirmarque por debajo de los puros enunciados constitucionales, con sus ambigüedades y su vaguedad, con sus márgenes de indeterminación semántica, sintáctica y hasta pragmática, existe un orden constitucional de valores, un sistema moral constitucional, bien preciso y dirimente. En lo epistemológico, el cognitivismo resultante de afirmar que las soluciones precisas y necesarias que 
de ese orden axiológico constitucional se desprenden pueden ser conocidas y consecuentemente aplicadas por los jueces. En lo político y social, el elitismo de entender que sólo los jueces o prioritariamente los jueces, y en especial los tribunales constitucionales, están plenamente capacitados para captar ese orden axiológico constitucional y lo que exactamente dicta para cada caso, razón por la que poseen los jueces el privilegio político de poder enmendar al legislador excepcionando la ley y justificando en el caso concreto la decisión contra legem que será decisión pro constitutione, por cuanto que es decisión basada en algún valor constitucional (GARCíA AMADO 4).

Bueno, esa caracterización podría convenir más o menos a los autores que él considera como "neoconstitucionalistas", pero siempre y cuando esas notas las formulase en términos "no rotundos", lo que supone, claro está, un cambio cualitativo: construir un concepto distinto al que él construye. O sea, hay una forma de defender el objetivismo y el cognoscitivismo moral y de reconocer el papel destacado que la jurisdicción (especialmente la constitucional) tiene en nuestros sistemas que, efectivamente, cuadra con lo sostenido por algunos autores llamados comúnmente "neoconstitucionalistas". Pero con ello nos estaríamos refiriendo a algo tan distinto a lo que GARCíA AMADO parece tener en mente que, si se quiere evitar la confusión, sería mejor elegir otra expresión, por ejemplo, "constitucionalismo teórico" (sin el "neo") o "postpositivismo" o bien "constitucionalismo postpositivista". Bastante distinto a los anteriores, al menos en principio, es el planteamiento de Luis PRIETO. Yo creo que lleva toda la razón al afirmar que "lo primero que llama la atención del neoconstitucionalismo es que parece ser una corriente de 
pensamiento con muy pocos militantes" y que "los autores que suelen citarse como principales impulsores del movimiento, muy heterogéneos entre sí, por otra parte, no suelen calificarse a sí mismos como neoconstitucionalistas", a lo que añade que: "a su vez, quienes hacen uso de esa expresión generalmente adoptan un sentido crítico y en ocasiones destructivo" (PRIETO 19). También me parece que acierta al pensar que lo que parece haber detrás del término es una discusión acerca de los desafíos que los cambios ocurridos en los sistemas constitucionales plantean a la teoría tradicional del Derecho, al positivismo (PRIETO 20). Pero lo que parece más discutible es la solución por la que aboga: la de hablar de "neoconstitucionalismos" (en plural). En su opinión, la heterogeneidad de planteamientos que puede encontrarse entre los autores a los que usualmente se denomina como neoconstitucionalistas es tal que no cabe considerar que con ello se designa una temática o una teoría, sino más bien una filosofía del Derecho del mismo tipo que el iusnaturalismo o el positivismo jurídico: una filosofía del Derecho -añade" tan totalizadora y pluralista como pueden ser estas dos últimas, o incluso más, por cuanto combina elementos de ambas procedencias [iusnaturalistas y positivistas]" (PRIETO 72). Y digo que me parece discutible, porque a lo que ello da lugar es a englobar bajo un mismo rótulo concepciones no sólo distintas entre sí sino, en muy buena medida, incompatibles, lo que no puede producir otra cosa que confusión: el arco trazado por PRIETO iría desde GARCÍA FIGUEROA hasta FERRAJOLI, pasando por DWORKIN, ALEXY O NINO. Dicho de otra manera, lo que él hace es considerar el rótulo como un verdadero cajón de sastre: al parecer, quien no sea ni positivista ni iusnaturalista, en el sentido más o menos tradicional de esas expresiones, estaría hoy condenado a ser neoconstitucionalista. Yo no lo creo. 
En fin, una caracterización del "neoconstitucionalismo" que recientemente ha dado lugar a una profusa discusión es la que lleva a cabo un autor muchas veces calificado como tal, como "neoconstitucionalista", pero, en su opinión, de manera errónea. Me refiero a Luigi FERRAJOLI y a su trabajo Constitucionalismo principialista y constitucionalismo garantista FERRAJOLI (2012) en el que defiende una serie de tesis que tienen una continuación en su último libro La democracia a través de los derechos (FERRAJOLI 2014).

En el primero de esos dos textos, FERRAJOLI contrapone dos tipos de "constitucionalismo jurídico", entendida esta expresión en el sentido de una teoría o filosofía del Derecho. El primero, el principialista o argumentativo, sería, en su opinión, al menos "tendencialmente", iusnaturalista y se caracterizaría por sostener la tesis de la conexión (intrínseca o necesaria) entre el Derecho y la moral; debido a la contraposición fuerte entre principios y reglas, y por atribuir un papel central a la ponderación en el ejercicio de la jurisdicción. Mientras que el constitucionalismo que él defiende, el normativo o garantista, niega esas tres tesis $\mathrm{y}$, a diferencia del primero, sería una concepción positivista del Derecho; mejor aún, según FERRAJOLI, su concepción del Derecho -cuya completa exposición se encontraría en su monumental Principia juris (FERRAJOLI 2011)-, supone algo así como la culminación o el perfeccionamiento del positivismo jurídico. FERRAJOLI considera, por otro lado, que la primera de esas dos concepciones (comúnmente denominada "neoconstitucionalista") es la más difundida en nuestros días, y de ahí su empeño por poner de manifiesto sus debilidades teóricas y sus peligros prácticos. Por positivismo jurídico, por otro lado, entiende "una concepción y/o un modelo de derecho que reconozcan como Derecho a todo conjunto de normas puestas o producidas por quien está 
habilitado para producirlas, con independencia de cuales fueren sus contenidos y, por tanto, de su eventual injusticia" (FERRAJOLI Constitucionalismo principalista 12).

Pues bien, FERRAJOLI es crítico tanto en relación con los autores iuspositivistas (normativistas o realistas) que, como es el caso de los genoveses, estarían anclados en un modelo del pasado, el del Estado legislativo de Derecho, como también en relación con los que defienden la primera de las concepciones constitucionalistas a la que me he referido. FERRAJOLI presenta por ello su constitucionalismo garantista como una vía media entre el paleo-positivismo y el neoiusnaturalismo, como la única teoría capaz de satisfacer las exigencias del constitucionalismo contemporáneo.

Los autores a los que califica de paleopositivistas son, además de los de la escuela genovesa, KELSEN, BOBBio y, en general, todos aquellos que no habrían tenido en cuenta (o que no habrían tenido en cuenta suficientemente) el fenómeno de la constitucionalización de nuestros derechos, ocurrido después de la Segunda Guerra Mundial. Ese fenómeno, para él, consiste esencialmente en la existencia de Constituciones rígidas. En su opinión, esa subordinación de la ley a la Constitución implica todo un cambio de paradigma teórico que se plasma en la existencia de dos niveles de normatividad y de validez jurídica: la validez simplemente formal o vigencia (conformidad de las normas con criterios formales y procedimentales), y la validez plena (conformidad, además, con los criterios sustantivos establecidos en la Constitución, en los principios y en los derechos fundamentales). Es esa duplicidad de niveles lo que le lleva a concebir de una manera distinta (distinta a la de los positivistas clásicos) tanto el concepto y la estructura del Derecho como la 
ciencia del Derecho (que ahora sería también normativa) y la jurisdicción (que pasaría a ser una jurisdicción comprometida con los principios constitucionales, aunque no activista).

$\mathrm{Y}$ a quienes defienden que el constitucionalismo sí exige un nuevo paradigma en la teoría del Derecho, aunque no pueda tratarse ya de un paradigma positivista, FERRAJOLI opone: la tesis de la separación (conceptual o metodológica) entre el Derecho y la moral; una concepción que, sin negar del todo la existencia de principios, tiende a considerar el Derecho (y, en particular, los derechos fundamentales) de manera casi exclusiva como un conjunto de reglas; y una concepción de la jurisdicción centrada en la subsunción y que no deja espacio para la ponderación. Ahora bien, las críticas que FERRAJOLI dirige a los autores a los que engloba dentro de los rótulos de "neoconstitucionalismo", "constitucionalismo principialista o argumentativo" o "neoiusnaturalismo" (entre otros, DWORKIN, ALEXY o NINO), están también, en mi opinión, claramente distorsionadas (ATIENZA 2012). FERRAJOLI piensa, al igual que pensaba COMANDUCCI, que los constitucionalistas no positivistas identifican la justicia, la moral, con las normas constitucionales e incurren, por ello, en una especie de "legalismo ético", en el que tradicionalmente cayó tanto cierto tipo de iusnaturalismo como lo que suele llamarse el iuspositivismo ideológico; para ellos el Derecho no es un conjunto de normas establecidas por la autoridad, sino, esencialmente, una serie de principios morales que los juristas podrían interpretar de manera más o menos arbitraria (sin sujeción a los textos legales y constitucionales); al sustituir la subsunción (en cuanto método de aplicación de las reglas) por la ponderación (que sería el método característico para manejar los principios) estarían promoviendo la libre creación del Derecho por parte de los jueces y, en consecuencia, el activismo judicial. 
Me parece que lo dicho hasta ahora es suficiente para entender por qué yo decía al comienzo que no se podía saber qué es eso del neoconstitucionalismo. No se puede saber, y no tanto porque se trate de un término desafortunado (por sus muchas ambigüedades) y de un concepto difuso, impreciso (al fin y al cabo, qué concepto no lo es), sino más bien porque estamos frente a algo así como un espantapájaros conceptual construido por algunos autores iuspositivistas para oponerse a ciertas tesis que cuestionan postulados básicos de ese paradigma. Como hemos visto, los críticos del neoconstitucionalismo identifican una serie de notas que caracterizarían a ese concepto y que realmente son ampliamente coincidentes. Pero el problema está en que las presentan de una manera, por así decirlo, grotesca (como se hace cuando se construye un espantapájaros), lo que seguramente explica el hecho muy curioso observado por PRIETO: son muy pocos los autores que se califican a sí mismos de "neoconstitucionalistas" y, desde luego, no parecen haberlo hecho ninguno de los que con mayor frecuencia aparecen en la lista -DWORKIN, ALEXY, NINO y ZAGREBELSKY-, mientras que un autor que ha sido $-\mathrm{y}$ es-considerado por muchos como neoconstitucionalista, Luigi FERRAJOLI, ha rechazado explícitamente esa denominación FERRAJOLI (2012) ... aunque no ha tenido tampoco empacho en adjudicársela a los anteriormente mencionados y a todos cuantos, aceptando la necesidad de construir un nuevo paradigma teórico para el Derecho del Estado constitucional, rechazan que ese paradigma pueda seguir siendo positivista. 
De todas formas, es también un hecho innegable que algunos juristas teóricos $\mathrm{y}$, sobre todo, prácticos (de manera muy particular en Latinoamérica) parecen haber aceptado ese rótulo como identificador de su manera de concebir el Derecho. Por ejemplo, según Humberto ÁVILA, el neoconstitucionalismo habría inspirado la Constitución Federal brasileña de 1988 y, en particular, la aplicación del Derecho constitucional en ese país durante las últimas décadas. Pero de nuevo nos encontramos (él da una lista de teóricos del Derecho brasileños "neoconstitucionalistas") con una caracterización sumamente difusa: "principios en vez de reglas (o más principios que reglas); ponderación en lugar de subsunción (o más ponderación que subsunción); justicia particular en vez de justicia general (o más análisis individual y concreto que general y abstracto); Poder judicial en vez de Poder legislativo o Ejecutivo (o más Poder judicial y menos Poder legislativo y ejecutivo); Constitución en sustitución a la ley (o mayor o directa aplicación de la Constitución en vez de la ley" (H. ÁvILA 126). Y su conclusión es que "los mencionados cambios fundamentales de la teorización y aplicación del Derecho constitucional, preconizados por el movimiento "neo-constitucionalista" (...) no encuentran soporte en el ordenamiento constitucional brasileño" (H. ÁvILA 145). Y en Ecuador es frecuente considerar que la Constitución de 2008 está también dentro de la órbita del neoconstitucionalismo; hay incluso una sentencia del Tribunal Constitucional de ese país (de 23 de julio de 2009) en la que se afirma que "la ciencia jurídica que rige al Estado ecuatoriano es el neoconstitucionalismo" PONCE (2010). Pero uno de los principales adalides del movimiento neoconstitucionalista ecuatoriano, Ramiro ÁVILA, aclara que su "neoconstitucionalismo transformador" tiene matices diferenciadores con respecto al "neoconstitucionalismo europeo continental" (R. ÁVILA 17) y, de hecho, caracteriza su concepción como una síntesis (a decir verdad, una difícil síntesis) entre el garantismo ferrajoliano y el pluralismo jurídico de BOAVENTURA de SOUSA SANTOS. 
De manera que la propuesta que yo quiero hacer aquí es la de utilizar el término de "neoconstitucionalismo" (obviamente se trata de una definición estipulativa) sólo para los autores que, efectivamente, aceptan esa denominación y que tal vez (esto lo digo con muchas dudas) podrían ser caracterizados de acuerdo con las notas que los iuspositivistas atribuyen a ese concepto. Pero esto quiere decir entonces que en la teoría del Derecho contemporánea, podríamos hacer una primera gran división entre, por una parte, quienes consideran que los cambios ocurridos con el fenómeno de la constitucionalización de nuestros Derechos no necesitan de un nuevo paradigma teórico, sino que de ellos puede darse cuenta permaneciendo en el positivismo, digamos, clásico: con acentos más bien normativistas o, por el contrario, realistas; $\mathrm{y}$, por otra, quienes defienden que la constitucionalización del Derecho requiere de un nuevo paradigma teórico. Y, dentro de este segundo grupo, habría, a su vez, que hacer estas divisiones:

1. Los constitucionalistas positivistas, como FERRAJOLI;

2. Los constitucionalistas no positivistas o postpositivistas, COMO DWORKIN, ALEXY, NINO O ZAGREBELSKY;

3. Los neoconstitucionalistas (que sin duda no es una clase vacía, pero sí menos poblada de lo que se piensa); y (quizás),

4. Los constitucionalistas iusnaturalistas ${ }^{3}$.

Si yo decía al comienzo que, a pesar de no saber muy bien lo que es el neoconstitucionalismo, de lo que sí estoy seguro es de

En un reciente trabajo, VIGo (2014) habla de un "neoconstitucionalismo iusnaturalista" que se distinguiría deloqueyollamoaquí "constitucionalismo postpositivista", fundamentalmente porque estos asumirían una inspiración kantiana (constructivista) en materia de ética, contrariamente a los iusnaturalistas, que serían personalistas o aristotélicos. 
no serlo, es porque, efectivamente, no comparto ninguna de las notas formuladas por POZZOLO, COMANDUCCI, etc., mientras que mi concepción del Derecho está muy próxima a la de autores como ALEXY, DWORKIN o NINO, y creo que no muy distante a la de ZAGREBELSKY, en el sentido de que me parece compartir el fondo de lo que este último sostiene, si bien la formulación teórica de sus tesis no siempre me parece suficientemente clara y precisa.

En concreto, el tipo de teoría del Derecho que yo defiendo es:

1. Constitucionalista;

2. No positivista;

3. Basada en la unidad de la razón práctica, lo que supone negar que pueda trazarse una separación tajante (en el plano conceptual) entre el Derecho y la moral;

4. Que defiende un objetivismo moral mínimo;

5. Reconoce la importancia de los principios; $y$,

6. De la ponderación; así como,

7. El papel activo de la jurisdicción; y,

8. Subraya el carácter argumentativo del Derecho.

Mostraré ahora cómo creo que deben entenderse esos rasgos, lo que configura una concepción del Derecho claramente separada de la positivista y de la, así llamada, neoconstitucionalista y que, por lo demás, no supone para nada una vuelta al Derecho natural. 


\section{3.}

Para que el constitucionalismo sea un rasgo distintivo de una teoría del Derecho no basta, obviamente, con reconocer el fenómeno de la constitucionalización del Derecho que, con grados distintos, caracteriza a muchos de los sistemas jurídicos del mundo occidental. Constitucionalistas serán, únicamente, las concepciones del Derecho que interpretan ese fenómeno de una cierta manera.

Así, no cabría llamar propiamente constitucionalista a una teoría del Derecho que considera que lo que distingue a las normas constitucionales es única o preponderantemente un elemento de tipo formal: la jerarquía normativa o la rigidez constitucional. Por eso, no son constitucionalistas las teorías a las que FERRAJOLI tacha de paleopositivistas, que tienden a subrayar la continuidad existente entre las normas legisladas y las constitucionales y a negar, por ello, la necesidad de construir un nuevo paradigma en la teoría del Derecho. Pero tampoco lo es, o no lo es del todo, la concepción del propio FERRAJOLI, pues, a pesar de subrayar la diferencia entre el nivel legislativo y el constitucional (que, como se recordará, le llevaba a plantear los dos conceptos de validez que, a su vez, tiene como consecuencia una forma comprometida de entender la ciencia del Derecho y la jurisdicción), él sigue pensando en la constitución en términos puramente formales y avalorativos: también para él, las normas constitucionales son, simplemente, las que tienen una jerarquía superior a las demás, garantizada mediante la existencia de tribunales constitucionales y que no pueden cambiarse de la misma manera que las otras, 
sino mediante un procedimiento agravado. Pero lo que FERRAJOLI niega es que el Derecho del Estado constitucional se caracteriza también por rasgos sustantivos, valorativos: por el reconocimiento y protección (mediante las técnicas que se acaban de señalar) de los derechos fundamentales. Se me dirá que, precisamente, toda la construcción teórica de FERRAJOLI está dirigida a cumplir este último objetivo: la garantía efectiva delos derechos fundamentales. Pero ocurre que sus prejuicios positivistas le llevan a definir los derechos fundamentales en términos puramente formales, avalorativos, y a negar que tenga sentido incluso plantearse la pregunta del fundamento (moral) de los derechos: "los valores morales y políticos últimos no se demuestran (...) simplemente se eligen, se postulan y se defienden", escribe en su último libro (FERRAJOLi La democracia a través del Derecho 104). De ahí que Josep AGUILó (2012), en frase feliz, haya podido afirmar que el de FERRAJOLI es un "constitucionalismo imposible": si se asumen sus postulados teóricos, no es posible obtener (o aproximarse a) los objetivos del Estado constitucional.

Tampoco serían propiamente constitucionalistas los autores neoconstitucionalistas, de acuerdo con la caracterización que de esa concepción hacían sus críticos positivistas. En este caso, no lo serían por exceso, esto es, por su tendencia a identificar todo el Derecho con la Constitución (recuérdese: "más Constitución que ley"), interpretada además de la manera libre (o arbitraria) que les atribuyen sus críticos, lo que equivale, efectivamente, a prescindir del carácter autoritativo del Derecho. Un rasgo típico del neoconstitucionalismo sería, pues, el de no tener en cuenta a las leyes a la hora de solucionar un problema jurídico e irse directamente a la Constitución, o incluso el de prescindir del tenor literal de un artículo (una regla) de la Constitución y basarse directamente en los principios y valores constitucionales 
para la resolución de un problema. Un ejemplo de esto último. La Constitución ecuatoriana (no se olvide, de 2008) contiene un artículo que define inequívocamente el matrimonio como la unión entre un hombre y una mujer. Sin embargo, algunos juristas (supuestamente neoconstitucionalistas) no creen que eso impida que pueda dictarse válidamente una ley que reconozca el matrimonio entre personas del mismo sexo: bastaría con argumentar -según ellos- que el no reconocimiento de ese tipo de matrimonio iría contra el principio de no discriminación por razón de sexo ATIENZA (2013).

Esto último me permite aclarar una crítica que es usual, como hemos visto, dirigir a los constitucionalistas no positivistas y que, en mi opinión, no pasa de ser una invención de sus críticos: el incurrir en legalismo ético o positivismo ideológico, al identificar la Constitución (el Derecho) con la justicia. Pero ninguno de los autores que he calificado de postpositivista sostiene eso, sino que, explícitamente, reconocen que puede haber normas jurídicas injustas. Considerar que la Constitución contiene un ingrediente valorativo no supone pensar que exista en la misma un orden de valores bien preciso. Al contrario. Las Constituciones son, o suelen ser, documentos típicamente ambiguos, puesto que reflejan las ideologías contrapuestas de las fuerzas políticas y sociales que las han impulsado; el acuerdo en cuanto a las finalidades y los valores que se expresa en una Constitución suele ser por ello precario o, si se quiere, está formulado en términos muy abstractos. De ahí la importancia de la interpretación en relación, por ejemplo, con los enunciados de derechos fundamentales. Por supuesto, no todo es posible, no todo está abierto, en cuanto al significado de los derechos. Pero los textos de nuestras Constituciones ofrecen casi siempre, o al menos con mucha frecuencia, al jurista la posibilidad de llegar 
a una solución justa sin salirse del Derecho; como he dicho, con excepciones: en relación con el matrimonio entre personas del mismo sexo, la Constitución ecuatoriana no parece ofrecer una solución justa -conforme con la moral justificada-, pero sí, por ejemplo, la española. Para lograr arribar a esa solución, eso sí, se necesita interpretar la Constitución a la luz de alguna filosofía moral y política de carácter sustantivo; para decirlo con DWORKIN, habrá que remontarse a la filosofía que sea compatible con los materiales autoritativos del Derecho y que suponga el mayor desarrollo de los fines y valores que conforman la práctica constitucional. El jurista constitucionalista no parte, pues, de la existencia de un orden preciso de valores, sino que, si se quiere, se esfuerza por encontrarlo o construirlo... aunque no siempre lo logre. Su posición, cabria decir, es semejante a la del médico. No siempre se pueden curar las enfermedades, pero sería un extraño profesional de la medicina el que pensara que procurar curar las enfermedades no forma parte de sus tareas.

De manera que el constitucionalismo no es una ideología idealista, ingenua, que considera que el Derecho del Estado constitucional es el mejor de los Derechos posibles y que nuestras Constituciones se identifican sin más con la moral justificada. Ese Derecho es simplemente el mejor de los históricamente existentes, y no lo es por consideraciones formales, sino de carácter sustantivo: por los valores que trata de proteger. Por lo demás, ese modelo está hoy en riesgo por lo que se refiere al Derecho estatal y no ha penetrado tampoco en otras esferas jurídicas que son incluso más decisivas que las estatales para garantizar los derechos fundamentales de la gente. En este último aspecto no cabe sino adherirse al proyecto político que FERRAJOLI (2014) defiende en su último libro. El paradigma constitucional necesita una doble ampliación: en sentido extensivo, lo que supone llevar el 
paradigma a todos los poderes (con la constitucionalización tanto del Derecho internacional como del Derecho privado y comercial de la globalización); y en sentido intencional, reforzando la garantía de todos los derechos. Ese proyecto político supone sin duda cambios radicales que configuran una especie de programa de lege ferenda para el jurista.

La crítica fundamental que cabe dirigir al positivismo jurídico es que se trata de una concepción demasiado pobre del Derecho, que no consigue dar cuenta de la complejidad de la experiencia jurídica, ni ofrece tampoco el instrumental teórico adecuado para que el jurista pueda desarrollar la que tendría que ser su tarea distintiva en el marco del Estado constitucional: la protección y el desarrollo de los derechos fundamentales. No puede hacerlo porque el positivista reduce el Derecho a una sola dimensión: la autoritativa, dejando fuera el componente de valor. Es a lo que le obliga la tesis de la separación entre el Derecho y la moral. La otra tesis que caracteriza el positivismo jurídico, la de las fuentes sociales del Derecho, o sea, que el Derecho no es algo natural, sino una construcción humana, relativa a las sociedades y a la historia, hoy no puede considerarse más que como un hecho indubitable, algo que nadie sensatamente podría discutir.

De manera que lo distintivo de las concepciones constitucionalistas pero no positivistas del Derecho es la afirmación de la naturaleza dual del Derecho que puede expresarse de distintas maneras. Una de ellas consiste en ver el Derecho no sólo como un conjunto de reglas, sino también de principios (el modelo clásico dworkiniano). Otra, en distinguir, como hace ALEXY, un componente de positividad y otro de idealidad en el Derecho, vinculado este último con la pretensión de corrección. O en considerar, en lo que tanto insistió NINO, que las normas jurídicas no suponen por 
sí mismas razones justificativas autónomas, de manera que el razonamiento jurídico tiene que abrirse hacia las razones morales, lo que se conecta con la tesis de que el Derecho puede definirse (puede conceptualizarse, según los propósitos y los contextos) tanto descriptiva, como normativa y valorativamente. $\mathrm{O}$ bien, como hace ZAGREBELSKY, distinguiendo un aspecto formal $\mathrm{y}$ un aspecto material en el Derecho, aunque este último aspecto parece reducirlo a la moral social (ZAGREBELSKY 32).

De nuevo, la dualidad de planos en el interior del Derecho del Estado constitucional que establece FERRAJOLI (y que le lleva a distinguir entre la validez formal y la sustantiva o plena de las normas) le aproxima algo a los anteriores autores, pero sigue subsistiendo una diferencia fundamental que hace que FERRAJOLI sea efectivamente (si se quiere, coherentemente) un autor iuspositivista: la distinción que él traza tiene lugar dentro del Derecho entendido exclusivamente como un conjunto de normas fijadas por una autoridad (legislativa o constitucional). No queda, por lo tanto, espacio para los valores lo que, inevitablemente, supone una amputación de la experiencia jurídica: la práctica (las prácticas) del Derecho no pueden comprenderse sin ese componente.

La concepción neoconstitucionalista hay que entenderla también como una reacción contra el positivismo jurídico, contra una visión del Derecho que pone el foco en las reglas, en la positividad, en las formas, y se olvida por ello de la justicia. Pero también en este caso habría que decir que los autores neoconstitucionalistas llevan demasiado lejos esa actitud crítica y se olvidan, por así decirlo, de los valores del legalismo. La suya es también una visión unidimensional del Derecho que incurre en la ingenuidad de pensar que los valores del Estado constitucional pueden alcanzarse sin necesidad de someterse a los límites, las 
constricciones, que impone el sistema de Derecho positivo. No se dan cuenta de que aquí ocurre como con la famosa paloma de Kant, que creía que podría volar aún mejor sin la resistencia del aire. Pues bien, la "resistencia" del Derecho positivo (digamos, las exigencias del principio de legalidad) es también, como elocuentemente nos ha recordado LAPORTA (2007), una condición de posibilidad para que pueda desarrollarse, entre otros, el valor de la autonomía.

En mi opinión, la mejor manera de expresar la naturaleza dual del Derecho consiste en ver en el mismo no sólo un sistema, un conjunto de normas, sino también (sobre todo) una práctica social con la que se trata de alcanzar (de maximizar) ciertos fines y valores, pero permaneciendo dentro del sistema: jugando al juego del Derecho. Por eso, el Derecho es, en parte, algo que está ahí fuera, algo dado (las normas establecidas por la autoridad), pero también, y de manera todavía más fundamental, una actividad, una empresa, una praxis: algo que se va construyendo y en lo que todos participamos. Si se quiere, los fines abstractos de la empresa han sido siempre los mismos (lograr un cierto orden social, asegurar una cierta idea de justicia), pero los cambios en las condiciones históricas de las sociedades, que se traducen en cambios en el sistema jurídico, repercuten también en la manera de contemplar y de participar en esa actividad y, en definitiva, en la forma de concebir el Derecho. De manera que así como la positivización del Derecho que tuvo lugar en Europa a finales del XVIII y comienzos del XIX acabó con la idea del Derecho natural e inauguró la época del positivismo jurídico (el Derecho pasó a entenderse como una obra humana, relativa a cada sociedad histórica, y no ya como una ordenación de la conducta con validez para todas las sociedades), la constitucionalización del Derecho supone también el final del positivismo jurídico: el Derecho no 
es ya sólo el Derecho puesto por la autoridad, sino una creación humana cuyo sentido es el de satisfacer ciertos valores que se plasman en los derechos fundamentales; si se quiere, una síntesis entre el positivismo jurídico y cierta manera de entender el Derecho natural. En alguna ocasión, GONZÁLEZ VICÉN (1979) recordaba una frase de BLOCH que venía a decir que la escuela histórica del Derecho (una de las corrientes con las que se inicia el positivismo jurídico) había crucificado al Derecho natural en la cruz de la historia. Pues bien, lo que ha hecho en nuestros días el constitucionalismo es crucificar al positivismo jurídico en la cruz de la Constitución: nuestra idea del Derecho no puede ser ya puramente formal, sino que tiene que incorporar necesariamente elementos sustantivos y de valor. Por eso, el postpositivismo no significa, como supone FERRAJOLI, una regresión a una etapa prebenthamita en la teoría del Derecho, sino la conciencia de que la teoría del Derecho que hoy necesitamos construir tiene que ser necesariamente post-benthamita.

La tesis de la unidad de la razón práctica supone que, en el razonamiento práctico, las razones últimas son las de carácter moral, de manera que, por ejemplo, el razonamiento justificativo de un juez tiene necesariamente una dimensión moral. Pero eso no quiere decir que el razonamiento jurídico y el moral se confundan ni tampoco que el razonamiento jurídico sea un caso especial del razonamiento moral (como, en mi opinión de manera equivocada, sostiene ALEXY). No lo es (al menos, no en todas sus instancias), aunque sí puede decirse que todos los tipos de argumentación jurídica (que, claro está, es algo distinto a todos los supuestos concretos de argumentación jurídica) pueden justificarse según las reglas del discurso racional, moral: la argumentación de los jueces, de los legisladores, de los abogados... El razonamiento jurídico -por ejemplo, la motivación de un juez- goza de cierta 
autonomía con respecto al razonamiento moral debido, sobre todo, al carácter fuertemente institucionalizado del primero. NINO (1992) lo ha explicado muy bien. Según él, el razonamiento jurídico justificativo (por ejemplo, el de un juez) se mueve en dos niveles. En el primero, de carácter más básico, se deben articular las razones que legitiman esa práctica social basada en la Constitución. En el segundo nivel (cuando se trata de justificar acciones y decisiones: en el primero se justificaban instituciones) quedan excluidas las razones justificativas que sean incompatibles con la preservación de la Constitución; lo que quiere decir que puede haber (que hay) razones moralmente justificadas que, sin embargo, no pueden utilizarse en la argumentación jurídica.

Pues bien, lo que los positivistas (o, mejor, los positivistas metodológicos o conceptuales) no parecen ver es que la relación entre el Derecho y la moral es una cuestión compleja, también desde la perspectiva conceptual (nadie niega, como es bien sabido, que existan relaciones en un plano empírico o externo: que las normas jurídicas tengan causas o consecuencias morales). O sea, que desde ciertas perspectivas o en ciertos contextos es perfectamente posible (necesario) separar el Derecho de la moral, mientras que desde otros no puede hacerse: nada impide que un sociólogo, un historiador o un observador externo emita el juicio de que la norma $\mathrm{N}$ o el sistema $\mathrm{S}$ son jurídicos $\mathrm{y}$, sin embargo, injustos; pero un juez no puede identificar el Derecho aplicable a un caso (o, por lo menos, no puede hacerlo en muchas ocasiones), sin acudir a razones morales, ni puede, en consecuencia, justificar su decisión, sin recurrir a la moral.

Hablando en términos generales, los positivistas parecen empeñados en establecer entre el Derecho y la moral un límite preciso, pero esto parece ir claramente contra la realidad de 
nuestros sistemas jurídicos que contienen (sobre todo en sus Constituciones) enunciados con conceptos densamente morales (dignidad, libertad, igualdad, etc.); por no hablar del pluralismo jurídico o de la globalización del Derecho en cuanto fenómenos muy característicos de nuestras sociedades y que muestran que las fronteras entre el Derecho y el no Derecho son cada vez más fluidas. Pensemos, sin ir más lejos, en los informes que emite una comisión de bioética: ¿tienen carácter jurídico, moral o poseen una naturaleza más bien híbrida?, ¿y tendría mucho sentido empeñarse por adscribir ese tipo de práctica en exclusividad al campo del Derecho o bien al de la moral?

Mientras que el defecto de los neoconstitucionalistas es justamente el contrario. Siempre de acuerdo con sus críticos positivistas, el neoconstitucionalismo sería, en la expresión de GARCÍA AMADO, una concepción iusmoralista, que reduce el Derecho a la moral $y$, en consecuencia, es incapaz de dar cuenta de la especificidad del Derecho y del razonamiento jurídico. Así, es también como caracteriza a esa concepción FERRAJOLI, quien subraya además que, al reducir los derechos fundamentales a principios morales, el neoconstitucionalismo presenta una versión debilitada de los mismos, que pone en riesgo su efectiva protección.

Hay, por cierto, un tipo de positivismo jurídico (al que se suele denominar "inclusivo"), que acepta esta tesis de que la identificación del Derecho y la argumentación jurídica en el Estado constitucional suponen la utilización de criterios morales. Pero si siguen considerándose iuspositivistas es porque piensan que esa conexión metodológica o conceptual entre el Derecho y la moral es meramente contingente, no necesaria: podría haber sistemas jurídicos que no funcionaran de esa manera. A lo que parece fácil replicar que, puesto que esos no son los nuestros (ni ninguno 
que podamos fácilmente imaginar), y si lo que nos interesa es construir una teoría del Derecho que pueda servir precisamente para los Derechos del Estado constitucional, entonces no se ve qué sentido tiene seguir considerándose iuspositivista ....salvo el temor de romper con la tradición de pensamiento en la que uno se ha formado ATIENZA y RUIZ MANERO (2009).

El presupuesto de lo anterior es el objetivismo moral, aunque sea un objetivismo mínimo. Si no fuera así, esto es, si pensáramos que no cabe ningún tipo de objetividad en relación con el discurso que apela a valores morales, entonces lo que estaríamos haciendo es abrir un enorme hueco de arbitrariedad en la construcción de la teoría del Derecho y alentando también a una práctica jurídica (en especial la judicial) abusiva, puesto que el ejercicio de su poder sería necesariamente arbitrario, ya que no cabe control racional a propósito de los valores. Esto es básicamente lo que piensan los autores positivistas cuando critican lo que ellos entienden por "neoconstitucionalismo".

Ahora bien, el no cognoscitivismo en materia moral no fue en sus orígenes una señal de identidad del positivismo jurídico (el utilitarismo de BENTHAM es quizás la mejor prueba de ello). Y hoy sigue habiendo positivistas jurídicos que no son escépticos en materia de moral. Pero, sin embargo, los positivistas jurídicos del mundo latino (y no olvidemos que es en este ámbito en el que se habla de "neoconstitucionalismo") han solido defender en los últimos tiempos, en materia de teoría moral, concepciones que oscilan entre el emotivismo y el historicismo (un historicismo, digamos, débil). Por un lado (o algunos de ellos) parecería que en materia de filosofía moral se han quedado en los años cincuenta del siglo XX y siguen pensando, más o menos, como KELSEN o como Ross: el discurso moral (en lo que no tenga que ver con 
relaciones de carácter lógico-formal o instrumental) cae fuera del dominio de la razón; pertenece al terreno de los sentimientos, de las emociones; los valores morales se pueden compartir con otros (con muchos) y uno puede estar dispuesto a luchar por ellos, pero lo que no puede en sentido estricto es justificarlos (recuérdense las palabras de FERRAJOLI). Y, por otro lado (y sin necesidad de abandonar el emotivismo moral), no faltan tampoco quienes consideran que los derechos humanos son "conquistas históricas" que, al parecer, valen en la medida en que exista una convención que las respalden. ¿Habrá que decir lo mismo en relación con los "valores" del neoliberalismo (el individualismo, la insolidaridad) que parece estar convirtiéndose en la ideología ampliamente dominante entre amplias capas sociales en el mundo contemporáneo?

En la discusión en torno al objetivismo moral hay probablemente algunos malentendidos que conviene deshacer. Los críticos del objetivismo parecen pensar que los que defienden la objetividad de los valores, del discurso moral, postulan la existencia de entidades misteriosas que vendrían a ser el equivalente a los átomos en el mundo físico: lo que DWORKIN, irónicamente, ha llamado los "morons" (DWORKIN 43). Pero ser objetivista no significa -o no significa necesariamente-ser realista moral. Se puede muy bien pensar que los valores son propiedades que atribuimos a ciertas acciones y estados de cosas, pero no de manera arbitraria, sino porque satisfacen necesidades básicas de los individuos o les proveen de capacidades indispensables para desarrollar una vida buena. Y lo que se quiere decir cuando se habla de objetivismo moral es que cabe una discusión racional a propósito de esos valores últimos; no significa ingresar en el campo de la irracionalidad o del discurso puramente retórico, persuasivo. Otro error frecuente consiste en confundir el objetivismo con el absolutismo moral, la 
pretensión de corrección -cuando se sostiene en serio una tesis moral-, con la pretensión de verdad absoluta, con el dogmatismo y la intolerancia característicos del discurso religioso. Pero es todo lo contrario. Lo que hace el objetivista es exponer sus juicios al discurso racional, y en esto se diferencia precisamente tanto del escéptico como del absolutista. El objetivismo moral es, pues, una concepción falibilista (como pasa con la idea de verdad en la ciencia) de la corrección moral.

Es importante tener muy en cuenta que todo esto no es simplemente una discusión abstracta, sino que tiene consecuencias de gran trascendencia en relación con cómo conformar la ciencia del Derecho y la práctica jurídica. Pues al iusfilósofo escéptico en materia moral no le cabe otra opción que elaborar modelos muy prescriptivos (muy alejados de la realidad) en relación con la dogmática jurídica o con el ejercicio de la jurisdicción. Y de esta manera, en mi opinión, el precio que ha de pagar en términos prácticos es sumamente alto: la imposibilidad de incidir significativamente en la marcha de esas actividades, lo que viene a suponer casi una condena a la irrelevancia.

La predilección por los principios frente a las reglas que se atribuye a los neoconstitucionalistas (más principios que reglas) presupone aceptar una opción (que también afectaría a los positivistas), entre principios o reglas que no es, en mi opinión, otra cosa que una modalidad de la falacia de la falsa oposición. En el Derecho, en nuestros Derechos, no existe ningún problema de alguna relevancia para cuya solución no se requiera tanto de principios como de reglas. De manera que, en mi opinión, tan equivocados están quienes pretenden reducir el Derecho básicamente a reglas (los -mejor: algunos-positivistas), como quienes optan por la otra reducción (los neoconstitucionalistas) 
y no ven en el Derecho (o, al menos, en el Derecho del Estado constitucional) otra cosa que principios.

Un ejemplo de esto último lo ofrece GARCíA FIGUEROA que en España, me parece, es uno de los pocos filósofos del Derecho que se califica a sí mismo de neoconstitucionalista. En su opinión, el neoconstitucionalismo es una teoría del Derecho que no acepta la dicotomía entre reglas y principios, pero simplemente porque él cree que en el Estado de Derecho no existen reglas, sino que todas las normas serían principios. Lo que quiere decir con ello es que todas las normas tienen (o pueden tener) excepciones, esto es, pueden ser derrotadas y, por tanto, no pueden considerarse como reglas. Pone un ejemplo que, en su opinión, avalaría esta tesis de manera incontrovertible. Dejemos que lo cuente:

Hace unos meses, un bebé de nombre Noara necesitaba urgentemente un trasplante de hígado. Cuando son compatibles, esa operación puede practicarse entre personas vivas, pues el receptor sólo necesita un fragmento del órgano del donante. Felizmente Noara disponía de un donante idóneo: su propia madre, cuyo nombre era Rocío. El final previsiblemente feliz de la historia fue enturbiado por el apartado a) de la siguiente disposición legal contenida en el art. 4 de la Ley 30/1979, de 27 de octubre, sobre extracción y trasplante de órganos:

D1: "La obtención de órganos procedentes de donante vivo, para su ulterior injerto o implantación en otra persona, podrá realizarse si se cumplen los siguientes requisitos:

a) Que el donante sea mayor de edad". 
El contenido de esta disposición puede reducirse, a los efectos que nos interesan, a la siguiente norma:

N1: Prohibido a todos los menores donar órganos.

Pues bien, Rocío tenía dieciséis años y por tanto no le estaba permitido donar órganos ni siquiera a su propia hija. La norma N1 que le impedía a Rocío donar una parte de su hígado a su bebé es lo que los teóricos de la distinción entre reglas y principios se complacen en llamar "regla" (GARCÍA FIGUEROA 126 y 127).

La conclusión que extrae de ello es la siguiente:

[E]ste caso demuestra la inviabilidad de cualquier intento de configurar las normas (ya sean constitucionales o infraconstitucionale como el art. 4 de la Ley de trasplantes) como reglas (i.e. normas inderrotables) y además este caso pone de manifiesto que el positivismo jurídico está desenfocado en su visión de las relaciones entre Derecho y moral (...) Como acabo de señalar, el caso Noara demuestra que la norma N1 ("prohibido a toos los menores donar órganos") no es una regla y, por extensión, demuestra que no es posible hablar de reglas en un Estado constitucional. Un corolario de esta constatación sería que la dicotomía regla/principio no es adecuada(...)[T] odas las normas jurídicas en el Estado constitucional son principios (si asumimos la terminología al uso)(...) [E]stamos de acuerdo en rechazar la dicotomía regla/ principio, pero ahí acaba nuestro acuerdo: A Ferrajoli le sobra la categoría de principio y a mí me sobra la categoría de regla" (GARCíA FIGUEROA 129). 
Bueno, si a GARCÍA FIGUEROA le sobra la categoría de regla es, me parece, porque comete un error conceptual que consiste en confundir lo que es una razón excluyente con una razón no derrotable en ningún ámbito, en ninguna circunstancia, esto es, con una razón absoluta. Las reglas (si se quiere usar la terminología de RAZ) son razones excluyentes, peropueden serderrotadas, aunque sea excepcionalmente (a diferencia de los principios, que no son razones excluyentes, sino razones no perentorias). Esto, sin embargo, no quiere decir que no haya reglas, y que todas las normas sean, en este aspecto, idénticas. Y, efectivamente, el error de los neoconstitucionalistas es simétrico al que cometen algunos iuspositivistas (me parece que es el caso de GARCíA AMADO) cuando piensan que las reglas sólo pueden tener excepciones explícitas, pero no excepciones implícitas, lo que equivale a decir que no pueden ser derrotadas nunca.

A mí me parece obvio que ninguna de esas dos concepciones extremas puede servir para dar cuenta de nuestras prácticas jurídicas. Que lo que necesitamos es conjugar reglas y principios y buscar, por así decirlo, un equilibrio entre la certeza que procuran las reglas y la flexibilidad que requiere el manejo inteligente del material jurídico y que no es posible llevar a cabo sin los principios, es precisamente en los principios en donde se encuentra la justificación para aceptar en algunos casos la existencia de excepciones -implícitas, no formuladas en el texto de la ley-a las reglas.

La presunta necesidad de optar (en la teoría y en la práctica jurídica) entre subsunción y ponderación es un error que deriva en buena parte del anterior: otro ejemplo de la falacia de la falsa oposición. Y también aquí, tan absurdo, tan equivocado, es propugnar que el razonamiento justificativo del juez debe limitarse al esquema de la subsunción, como recurrir alegremente a la ponderación siguiendo el eslogan de "más ponderación que subsunción". 
Necesitamos obviamente los dos esquemas argumentativos, simplemente porque en ocasiones (pongámonos en la perspectiva de un juez) para la resolución de un caso se cuenta con una premisa normativa que es una regla (más exactamente, una regla de acción), mientras que en otras ocasiones el punto de partida no es una regla, sino un principio (o, mejor, una conjunción de principios que empujan hacia soluciones opuestas). Esto último puede ocurrir si se da alguna de estas dos circunstancias: que exista una laguna normativa en el nivel de las reglas, o que exista (se cree) una laguna axiológica, porque hay un desajuste entre (el significado textual de) las reglas y sus razones subyacentes, los principios que las dotan de sentido.

Me he referido en varias ocasiones (una de ellas, muy recientemente (ATIENZA y GARCÍA AMADO 2012) a cómo debe entenderse la ponderación y no es aquí cuestión de volver a repetirlo. Me limito a señalar que se trata de un procedimiento racional (formalizable desde el punto de vista lógico), en relación con el cual sí que pueden establecerse criterios de control racional, aunque no sean los de la lógica formal, sino los criterios de la racionalidad práctica.

Por lo demás, tampoco los criterios estrictamente lógicos son suficientes en el caso de la subsunción, puesto que su manejo supone el establecimiento de las premisas y esta última no es una operación lógico-deductiva. Y es también innegable que el razonamiento ponderativo supone siempre niveles mayores de discrecionalidad que el puramente subsuntivo y que, por lo tanto, debe recurrirse al mismo de manera excepcional, al tiempo que su uso requiere niveles particularmente exigentes de justificación.

Una consecuencia igualmente obvia de todo lo anterior es que el juez no debe incurrir ni en formalismo ni en activismo. Por 
supuesto, se trata de dos términos de no fácil precisión, pero yo diría, en principio, que el juez formalista es el que atiende únicamente al texto de la ley y no toma en cuenta las razones subyacentes a las mismas, de manera que se olvida de los fines y valores que caracterizan esa práctica. Mientras que el activista es el que no tiene en cuenta los límites del Derecho, actúa como si el Derecho no fuera para él una práctica autoritativa, como si los materiales jurídicos no fijaran ciertos límites, dentro de los cuales él debe permanecer porque, de otra manera, ya no estaría jugando al juego del Derecho, lo que significa que estaría poniendo en riesgo valores esenciales del Derecho (del Derecho del Estado constitucional) que no son puramente formales: no lo son porque -como antes decía- suponen condiciones para que puedan darse los otros, los valores materiales.

Yo creo que el defecto fundamental de la cultura jurídica en los países latinos sigue siendo la propensión hacia el formalismo. Y esa puede ser una explicación para el hecho de que muchos juristas comprometidos con un proyecto político de transformación social se sientan atraídos por el neoconstitucionalismo. Pero el formalismo no se combate ignorando que en la cultura del legalismo hay valores que es importante preservar, que el positivismo jurídico no implica necesariamente formalismo y que, en definitiva, un juez activo no es lo mismo que un juez activista...aunque los límites del activismo no pueden ser trazados exactamente de la misma manera en países de institucionalidad, digamos, fuerte, en los que existen instancias distintas a la judicial en condiciones de asegurar la tutela de los derechos fundamentales allí donde no llega la acción judicial, que en otros, de institucionalidad más débil, en los que la no actuación por parte del juez puede supone lisa y llanamente la no satisfacción de los derechos. 
Todos los anteriores rasgos del constitucionalismo no positivista se conectan de manera muy estrecha con la argumentación jurídica: el Estado constitucional supone, sin duda, mayores exigencias de argumentación (a los jueces y, en general, a los juristas) que el Estado de Derecho legislativo; un límite notable del positivismo jurídico -que ha sido puesto de manifiesto por diversos autores- es su carencia de una teoría de la argumentación; la tesis de la unidad de la razón práctica supone la incorporación en el Derecho de la argumentación moral; el objetivismo moral es un presupuesto para entender la exigencia de que los órganos públicos tengan que fundamentar sus decisiones; la importancia de los principios va ligada a un incremento y una complejidad creciente de la argumentación en el Derecho; como se echa de ver sobre todo a propósito de la ponderación y el modelo de juez bosquejado en el anterior apartado (ni formalista ni activista) podría definirse también como un juez argumentativo, que se toma en serio la obligación de fundamentar sus decisiones y, por ello, acepta también la existencia de ciertos límites: los que marcan la diferencia entre lo que es y lo que no es argumentable en el Derecho.

Pero eso no quiere decir que se trate de una teoría argumentativa del Derecho, en el sentido en el que usa esta expresión (FERRAJOLI 2012) para referirse a una teoría que reduce el Derecho a principios y defiende una concepción débil de los derechos fundamentales, pues estos (en cuanto meros principios) necesitarían ser ponderados con otros, con los cuales entrarían en incesante conflicto. Como ya se ha visto, el Derecho no puede reducirse ni a principios ni a reglas. El concepto de derechos fundamentales implica, en el nivel normativo, tanto reglas como principios, pero, además hay otro nivel, el valorativo, necesario para dar cuenta de manera satisfactoria de la noción de derechos 
fundamentales. Y, naturalmente, la afirmación de que alguien tiene un derecho no supone siempre un ejercicio de ponderación, pues muchas veces (la mayoría de las veces) los derechos están establecidos con claridad en una regla y su aplicación no hace surgir ningún conflicto entre derechos. Repitámoslo una vez más: el hecho de que las reglas pueden ser excepcionalmente derrotadas no supone que no podamos tener ninguna seguridad sobre la solución jurídica de los casos que regulan.

El constitucionalismo no positivista es una teoría argumentativa del Derecho en cuanto subraya que la práctica jurídica -y en especial en el Estado constitucional-tiene en buena medida un carácter argumentativo aunque, naturalmente, en el Derecho no todo es argumentación. Pero ser consciente de esa dimensión abre al jurista grandes posibilidades de actuación para transformar dicha práctica precisamente en el sentido de aproximarla a los valores del constitucionalismo. De ahí la importancia de desarrollar una teoría, cuya mayor virtualidad, en mi opinión, consiste en vincular, de una manera que cabría llamar "natural", la teoría con la práctica y, al mismo tiempo, la teoría del Derecho con las ciencias sociales y con la filosofía. Para ello se necesita un concepto de argumentación suficientemente amplio y sistemático que permita articular la dimensión lógico-formal con la dimensión material y la dimensión pragmática (retórica y dialéctica). Y que contribuya, por ello, a guiar a los juristas en la resolución de tres cuestiones capitales de su práctica: cómo entender y analizar una argumentación que ha tenido lugar en algún campo o instancia jurídica; cómo evaluarla; y cómo argumentar (ATIENZA 2013). 


\section{4.}

Soy muy consciente de que todo lo anterior lo he presentado de manera muy telegráfica y que necesitaría de un desarrollo pormenorizado (que, en parte, creo haber efectuado ya en otros lugares). Pero espero al menos haber sido capaz de ofrecer razones de suficiente peso para justificar estas tres tesis:

1. El llamado neoconstitucionalismo es una teoría con pocos adeptos y que se caracteriza básicamente, según sus detractores, por tesis insostenibles;

2. El positivismo jurídico, en cualquiera de sus modalidades, no es una concepción del Derecho que pueda dar cuenta del fenómeno del constitucionalismo y, con frecuencia, sus representantes incurren en errores que son simétricos a los de los neoconstitucionalistas; y,

3. La única concepción que puede ofrecer una guía al jurista que se mueve en el contexto de los Derechos del Estado constitucional es el constitucionalismo no positivista, que evita los errores o las exageraciones de las dos anteriores doctrinas y ofrece un modelo no unilateral y suficientemente complejo del Derecho. 


\section{BIBLIOGRAFÍA}

Aguiló, Josep. "El constitucionalismo imposible de Luigi Ferrajoli”, en FERRAJOLI, Luigi, 2012.

A TIEnZA, Manuel. Curso de argumentación jurídica, Madrid: Trotta, 2013.

,"Más allá del neoconstitucionalismo y del formalismo", en el Diario El Universo de Guayaquil (2-XI-2013); puede consultarse en el blog: lamiradadepeitho.blospot.com

, y GARCÍA AMADO, Juan Antonio. Debate sobre la ponderación, Lima-Bogotá: Palestra-Themis, 2012.

, y RUIZ MANERO, Juan. "Dejemos atrás el positivismo jurídico, en Para una teoría postpositivista del Derecho, Lima-Bogotá: Palestra-Themis, 2009.

ÁvILA, Humberto. "Neoconstitucionalismo: entre la "ciencia del Derecho" y el "Derecho de la ciencia", en Tendencias actuales del Estado constitucional contemporáneo. Tomo $\mathrm{V}$ : Neoconstitucionalismo y argumentación jurídica. Constitucionalismo y principio de proporcionalidad. Lima: Ara Editores, 2013.

ÁvILA, Ramiro. El neoconstitucionalismo transformador. El estado y el Derecho en la Constitución de 2008. Quito: Alberto Acosta y Esperanza Martínez editores, 2011. 
CARbonell, Miguel (ed.). Neoconstitucionalismo(s). Madrid: Trotta, 2003.

COMANDUCCI, Paolo. "Formas de (neo)constitucionalismo: un análisis metateórico" en CARBONEL, Miguel, 2003.

DWORKIN, Ronald. Justice for hedgehogs, Belknap: Harvard University, 2011.

Ferrajoli, Luigi. "Constitucionalismo principialista y constitucionalismo garantista", en Un debate sobre el constitucionalismo. (el libro se reproduce en el número 34 de la Revista Doxa). Madrid: Marcial Pons, 2012.

. La democracia a través de los derechos. Madrid: Trotta, 2014.

GARCÍA AMADO, JuanAntonio. "Sobre el neoconstitucionalismo y sus precursores", en Controversias constitucionales. Bogotá: Universidad del Rosario, F. Mantilla Espinosa (ed.), 2008; el texto puede consultarse en www.videa. edu.co/portal.

GarCía FIGUEROA, Alfonso. "Neoconstitucionalismo: Dos (o tres) perros para un solo collar. Notas a propósito del constitucionalismo justpositivista de Luigi Ferrajoli” en FERRAJOLI, LUIGI. 2012.

GonZÁLEZ VICÉn, Felipe. Estudios de filosofía del Derecho, Universidad de La Laguna, 1979.

LAPORTA, Francisco. El imperio de la ley. Una visión actual. Madrid: Trotta, 2007.

NinO, Carlos S. Fundamentos de Derecho constitucional. Buenos Aires: Ed. Astrea, 1992. 
PONCE, Juan E. Neoconstitucionalismo en el Ecuador. Quito: Corporación de Estudios y Publicaciones, 2010.

Pozzolo, Susana. "Neoconstitucionalismo y especificidad de la interpretación constitucional", en Revista Doxa 21. Volumen II, 1998.

- "Un constitucionalismo ambiguo" en CARBONELL, Miguel, 2003.

PrIETO, Luis. "Neoconstitucionalismos (Un catálogo de problemas y argumentos)", en Tendencias actuales del Estado constitucional contemporáneo, Tomo V: Neoconstitucionalismo y argumentación jurídica. Constitucionalismo y principio de proporcionalidad. Lima: Ara Editores, 2013.

VIGO, Rodolfo. “¿Dos o tres neoconstitucionalismos?”, en $E x$ legibus, N. ${ }^{\circ} 1$, octubre 2014.

ZAGREBELSKY, Gustavo. La ley y su justicia. Tres capítulos de justicia constitucional. Madrid: Trotta, 2014. 